\title{
Delay in diagnosis of influenza A (H1N1)pdm09 virus infection in critically ill patients and impact on clinical outcome
}

Francisco Álvarez-Lerma ${ }^{1,2,3^{*}}$, Judith Marín-Corral ${ }^{1,2}$, Clara Vila1', Joan Ramón Masclans ${ }^{1,2,4,5}$,

Francisco Javier González de Molina ${ }^{6}$, Ignacio Martín Loeches ${ }^{7}$, Sandra Barbadillo ${ }^{8}$, Alejandro Rodríguez ${ }^{4,9}$

and on behalf of the H1N1 GETGAG/SEMICYUC Study Group

\begin{abstract}
Background: Patients infected with influenza A (H1N1)pdm09 virus requiring admission to the ICU remain an important source of mortality during the influenza season. The objective of the study was to assess the impact of a delay in diagnosis of community-acquired influenza A (H1N1)pdm09 virus infection on clinical outcome in critically ill patients admitted to the ICU.

Methods: A prospective multicenter observational cohort study was based on data from the GETGAG/SEMICYUC registry (2009-2015) collected by 148 Spanish ICUs. All patients admitted to the ICU in which diagnosis of influenza A (H1N1)pdm09 virus infection had been established within the first week of hospitalization were included. Patients were classified into two groups according to the time at which the diagnosis was made: early (within the first 2 days of hospital admission) and late (between the 3rd and 7th day of hospital admission). Factors associated with a delay in diagnosis were assessed by logistic regression analysis.

Results: In 2059 ICU patients diagnosed with influenza A (H1N1)pdm09 virus infection within the first 7 days of hospitalization, the diagnosis was established early in 1314 (63.8\%) patients and late in the remaining 745 (36.2\%). Independent variables related to a late diagnosis were: age (odds ratio $(\mathrm{OR})=1.02,95 \%$ confidence interval (CI) 1.01-1. 03, $P<0.001)$; first seasonal period (2009-2012) $(\mathrm{OR}=2.08,95 \% \mathrm{Cl} 1.64-2.63, P<0.001)$; days of hospital stay before ICU admission $(\mathrm{OR}=1.26,95 \% \mathrm{Cl} 1.17-1.35, P<0.001)$; mechanical ventilation $(\mathrm{OR}=1.58,95 \% \mathrm{Cl} 1.17-2.13, P=0.002)$; and continuous venovenous hemofiltration ( $\mathrm{OR}=1.54,95 \% \mathrm{Cl} 1.08-2.18, P=0.016)$. The intra-ICU mortality was significantly higher among patients with late diagnosis as compared with early diagnosis ( $26.9 \%$ vs $17.1 \%, P<0.001)$. Diagnostic delay was one independent risk factor for mortality $(\mathrm{OR}=1.36,95 \% \mathrm{Cl} 1.03-1.81, P<0.001)$.

Conclusions: Late diagnosis of community-acquired influenza A (H1N1)pdm09 virus infection is associated with a delay in ICU admission, greater possibilities of respiratory and renal failure, and higher mortality rate. Delay in diagnosis of flu is an independent variable related to death.
\end{abstract}

Keywords: Influenza A (H1N1)pdm09 virus infection, Mortality, Critically ill, Early diagnosis, Late diagnosis, Outcome, ICU

\footnotetext{
* Correspondence: FAlvarez@parcdesalutmar.cat

${ }^{1}$ Service of Intensive Care Medicine, Hospital del Mar, Passeig Marítim 25-29,

E-08003 Barcelona, Spain

${ }^{2}$ Research Group in Critical Disorders (GREPAC), Institut Hospital del Mar

d'Investigacions Mèdiques (IMIM), Barcelona, Spain

Full list of author information is available at the end of the article
} 


\section{Background}

Since the 2009 H1N1 influenza pandemic, patients with influenza A (H1N1)pdm09 admitted to the ICU remain an important source of mortality during the influenza season [1, 2]. The importance of early diagnosis and prompt start of antimicrobial treatment has been shown consistently in critically ill patients with severe bacterial infection or severe sepsis [3-6]. In patients with influenza $A$, in most cases typically during epidemic periods, antiviral treatment is administered when diagnosis is suspected (within the first 48 hours of hospital admission), although diagnosis and treatment (between the 3rd and 7th day of admission) can be delayed because of the lack of clinical suspicion by the medical team or negative results in the first samples analyzed (false negatives) $[7,8]$.

Different studies have identified factors independently associated with mortality in patients diagnosed with influenza A (H1N1)pdm09 infection $[9,10]$ or in selected subgroups, such as patients older than 65 years of age [11], obesity [12], immunodeficiency viral infection (HIV) [13], chronic liver disease [14], childhood [15] and pregnancy [16], as well as in different presenting forms of infection (severe sepsis, septic shock, pneumonia) and ICU admission $[17,18]$. Also, other subsets of patients have been independently analyzed according to the presence of some factors, such as previous influenza vaccination [19], earliness of treatment with oseltamivir [20], use of corticoids [21] or macrolides [22], or the need for invasive or noninvasive mechanical ventilation on ICU admission or during the ICU stay [23]. However, the clinical impact of a delay in the diagnosis of influenza A (H1N1)pdm09virus infection is unknown, particularly in those patients ultimately requiring admission to the ICU.

The objective of the study was to analyze data available in a multicenter database of patients admitted to the ICU diagnosed with influenza A (H1N1)pdm09 virus infection, to determine clinical factors related to a delay in diagnosis and the impact on the outcome of patients. It was hypothesized that a delay in diagnosing influenza A (H1N1)pdm09 infection is associated with a worse clinical course and that early identification of influenza-infected patients can contribute to optimization of treatment.

\section{Methods}

\section{Design and study population}

This was a prospective, multicenter, observational cohort study. Between January 1, 2009 and December 31, 2015, data for all patients with microbiologically-confirmed diagnosis of influenza A (H1N1)pdm09 virus infection admitted to 148 ICUs throughout Spain were included in the GETGAG/SEMICYUC registry (Spanish Working Group on Severe Pandemic Influenza A (GETGAG) of the Spanish Society of Critical Care Medicine and
Coronary Units (SEMICYUC)). All patients with influenza symptoms admitted to the participating ICUs were tested for influenza A or B, and investigators voluntarily registered all influenza A (H1N1)pdm09-positive patients in the national registry. The identification of patients was anonymized and individual patient informed consent was not obtained given the noninterventional nature of the study. The GETGAG/SEMICYUC registry was approved by the Institutional Review Board of Hospital Joan XXIII University Hospital of Tarragona, Spain.

All patients admitted to the ICU with clinical manifestations of respiratory infection in which influenza $A$ (H1N1)pdm09 virus was identified during the first week of hospital stay were included in the study. The presence of influenza A (H1N1)pdm09 virus was confirmed by realtime polymerase chain reaction (rt-PCR) performed according to recommendations of the Centers for Disease Control and Prevention (CDC) [24]. Clinical manifestations included two or more of the following signs and symptoms: fever $\left(>38{ }^{\circ} \mathrm{C}\right)$, cough, bronchial expectoration, and myalgias associated with clinical signs of organ or system failure (respiratory failure, hemodynamic instability, renal failure, or altered consciousness). Exclusion criteria were patients younger than 15 years of age, patients diagnosed with influenza A (H3N2) or influenza B, and patients in whom diagnosis of influenza A (H1N1)pdm09 virus infection had been established from 7 days of hospital admission.

\section{Definitions}

Patients included in the study were classified into two groups according to the time at which the diagnosis of influenza A infection was made: early (within the first 2 days of hospital admission) and late (between the 3rd and 7th day of hospital admission). Definition of communityacquired pneumonia was based on recommendations of the American Thoracic Society/Infectious Diseases Society of America (ATS/IDSA) [25].

\section{Case report form}

A case report form (CRF) was designed for data collection, including demographics (age, sex), time-related variables (time between hospital admission and diagnosis of influenza A, length of hospital stay before ICU admission, length of ICU stay, total length of hospital stay), comorbidities, previous influenza vaccination, epidemics season (2009-2012, 2013-2015), severity of illness, presenting manifestations of infection (pneumonia, severe asthma, acute exacerbation episode of a chronic pulmonary disease, heart failure), treatments administered (antivirals, inotropic drugs, corticoids, mechanical ventilation, extrarenal depuration procedures), and intra-ICU mortality. The severity of infection was assessed according to the Acute Physiology and Chronic Health Evaluation 
(APACHE II) score [26] and the Sequential Organ Failure Assessment (SOFA) score [27] on ICU admission. Information was provided by physicians of the participating ICUs according to the patient's medical history, laboratory data, and radiological findings. The predicted mortality (based on APACHE II score) in the early and late diagnosis groups versus the observed mortality was calculated using the online APACHE II calculator (http://clincalc. com/IcuMortality/APACHEII.aspx).

\section{Statistical analysis}

Categorical variables are expressed as frequencies and percentages, and continuous variables as mean and standard deviation (SD) when data followed a normal distribution or as median and interquartile range (25th-75th percentile) when the distribution departed from normality. Differences between groups were analyzed with the chi-square $\left(x^{2}\right)$ test or the Fisher's exact test for categorical variables, and the Student's $t$ test or the Mann-Whitney $U$ test for continuous variables. Significant variables in the bivariate analysis were included in a multivariate logistic regression model to assess independent factors associated with late diagnosis and mortality. Odds ratios (ORs) and $95 \%$ confidence intervals (CIs) were calculated. Cumulative survival for patients with influenza A (H1N1)pdm09 virus infection according to time of diagnosis was assessed using the Kaplan-Meier plot. Statistical significance was set at $P<0.05$. Data were analyzed using the Statistical Package for the Social Sciences (SPSS, Chicago, IL, USA) for Windows 15.0.

\section{Results}

A total of 2421 patients diagnosed with influenza A (H1N1)pdm09 virus infection were included in the GETGAG/SEMICYUC registry. The diagnosis was established within the first week of hospital admission in 2059 (85.0 \%) patients, $1314(63.8 \%)$ of whom were classified into the early diagnosis group and 745 (36.2 \%) into the late diagnosis group (Fig. 1). Patients in the late diagnostic group, compared with those in the early diagnosis group, were significantly older, showed higher severity of illness, higher percentages of immunosuppression, hematological diseases, and chronic renal failure, required longer hospital and ICU stay, required invasive and noninvasive mechanical ventilation more frequently, required use of vasoactive drugs, corticoids, and extrarenal depuration procedures, and treatment with oseltamivir was prescribed more lately (Table 1 ).

In the logistic regression analysis, independent variables related to a delay in diagnosis of influenza A (H1N1)pdm09 virus infection were as follows: age $(\mathrm{OR}=1.02,95 \% \mathrm{CI}$ 1.01-1.03, $P<0.001)$; first seasonal epidemics (2009-2012) $(\mathrm{OR}=2.08,95 \%$ CI 1.64-2.63, $P<0.001)$; stay of in-patient care before ICU admission (OR $=1.26,95 \%$ CI 1.17-1.35,
$P<0.001)$; and need for mechanical ventilation $(\mathrm{OR}=1.58$, $95 \%$ CI 1.17-2.13, $P=0.002$ ) and continuous venovenous hemofiltration $(\mathrm{OR}=1.54,95 \% \mathrm{CI} 1.08-2.18, P=0.016)$ (Table 1). Patients admitted to the ICU within the first 48 hours of hospitalization showed a mean (SD) APACHE II score of 15 (7) vs 18 (8) for patients admitted after the first 48 hours $(P<0.001)$. Also the mortality rate was significantly different between ICU admission within 48 hours of hospitalization and after 48 hours $(19.4 \%$ vs $35.2 \%, P<0.001)$.

The intra-ICU mortality was $17.1 \%$ in the early diagnosis group (predicted $22 \%$ ) and $26.9 \%$ in the late diagnosis group (predicted $23.5 \%)(P<0.001)$. Time to event analysis showed an association between timing of influenza A (H1N1)pdm09 diagnosis and mortality (Fig. 2), although in both groups mortality was related to the severity level (APACHE II score) on ICU admission (Fig. 3). Independent of the severity level on admission, mortality was significantly higher in the late diagnostic group for APACHE II scores of $0-10$ and 21-30. Statistical significance was almost reached for APACHE II score of 11-20 $(P=0.062)$ and was not significant for scores $>30$ (Fig. 3). A further subanalysis regarding delay in oseltamivir therapy in relation to the date on which influenza A infection was diagnosed showed no significant differences in mortality ( $\leq 1$ day vs $>1$ day, $17.9 \%$ vs $22.8 \%, P=0.153 ; \leq 2$ days vs $>2$ days, $19.0 \%$ vs $23.3 \%, P=0.085$; $\leq 3$ days vs $>3$ days, $20.6 \%$ vs $23.2 \%$, $P=0.222$ ). In relation to immunosuppression, the mortality rate was higher in the group of late diagnosis of influenza A (H1N1)pdm09 virus infection than in the early diagnosis group both in the presence of immunosuppression ( $55.2 \%$ vs $40.6 \%, P=0.046)$ and in the absence of immunosuppression ( $22.7 \%$ vs $14.9 \%, P=0.001)$.

As shown in Table 2, independent factors significantly associated with intra-ICU mortality in patients diagnosed with influenza A (H1N1)pdm09 virus infection within the first week of hospital admission included the following: late diagnosis $(\mathrm{OR}=1.36,95 \% \mathrm{CI} 1.03-1.81$, $P<0.001)$; APACHE II score on ICU admission ( $\mathrm{OR}=$ $1.09,95 \%$ CI 1.07-1.11, $P<0.001$ ); hematological disease $(\mathrm{OR}=1.98,95 \%$ CI $1.23-3.19, P<0.001)$; need for mechanical ventilation $(\mathrm{OR}=4.84,95 \%$ CI $2.73-8.56$, $P<0.001)$; and use of continuous venovenous hemofiltration $(\mathrm{OR}=4.81,95 \%$ CI 3.31-7.01, $P<0.001)$.

\section{Discussion}

This study shows that diagnostic delay of communityacquired influenza A (H1N1)pdm09 virus infection in critically ill patients admitted to the ICU is a risk factor for mortality. Late versus early diagnosis of influenza was associated with more days of hospitalization before ICU admission, greater need for respiratory support and extrarenal depuration techniques, as well 


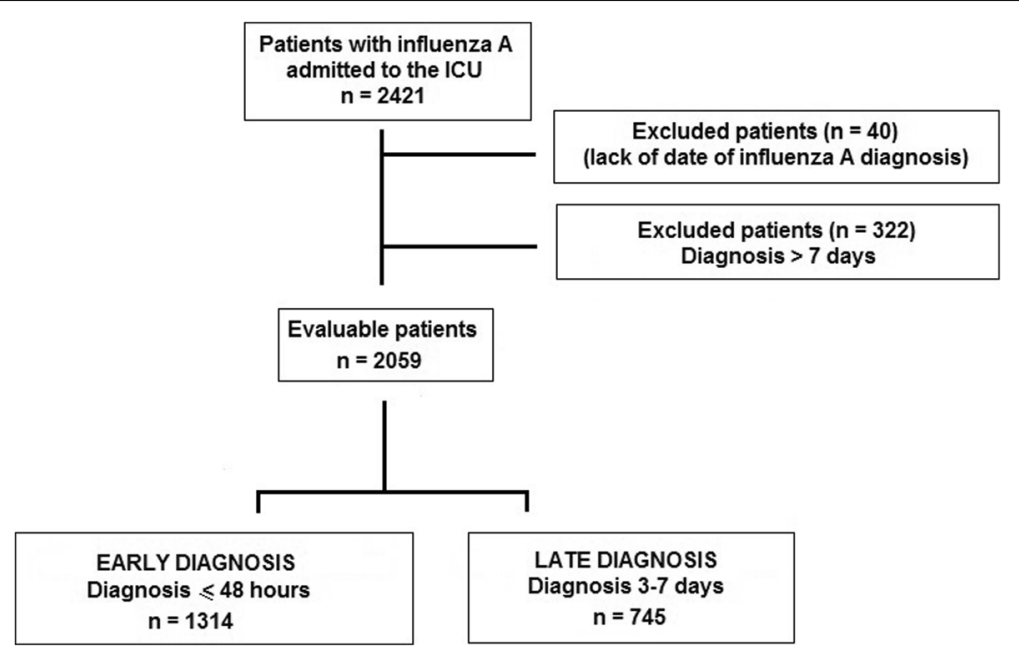

Fig. 1 Distribution of patients with influenza A (H1N1)pdm09 virus infection admitted to the ICU according to the date of diagnosis

as longer durations of stay in the ICU and in the hospital.

The selection of 7 days as a time limit for considering the community setting as the source of influenza A (H1N1)pdm09 virus infection is based on the limit established for the incubation period of the virus [28]. The incubation period estimated for the healthy population ranges between 2 and 4 days [29, 30], although in adult patients and in immunosuppressed patients a more prolonged period has been described [31]. The present study therefore considered that the origin of infection was the community for all patients with compatible symptoms of respiratory tract infection in whom a definitive diagnosis of influenza A (H1N1)pdm09 was made within the first week of hospital admission, whereas the origin was probably nosocomial when diagnosis was established from the second week of hospital admission.

Although the study was not designed to assess causes of delay in diagnosis of influenza A (H1N1)pdm09 virus infection (specific reasons were not included in the registry), it is likely that late diagnosis may be related to the lack of clinical suspicion of viral infection or to negative results in the respiratory samples initially analyzed. The first case usually corresponds to patients with suspicion of bacterial infections treated empirically with antimicrobials with poor clinical response, and the second case to difficulties in obtaining and/or processing adequate samples. In the first publications of patients admitted to the ICU with influenza A (H1N1)pdm09 virus infection during the $2009 \mathrm{H} 1 \mathrm{~N} 1$ influenza pandemic, upper respiratory samples were negative in up to $20 \%$ of cases, so the definitive diagnosis could have been established in samples recovered from the lower respiratory tract $[7,8]$. Obtaining new samples from bronchial aspirates is thus recommended for patients with suspected severe viral pneumonia and negative oropharyngeal samples, and bronchoalveolar lavage samples should be collected only if results of bronchial aspirates are persistently negative [32].

In our country, we found a decrease in the number of patients with late diagnosis during the second influenza epidemic season, which may be due to a training effect in the management of patients with clinical suspicion of influenza A (H1N1)pdm09 virus infection especially during outbreaks and due to greater availability of techniques for rapid diagnosis.

In the present study, clinical characteristics associated with diagnostic delay of influenza A (N1H1)pdm09 were examined. Although clinically relevant differences between patients in the early and late diagnosis groups were found for a number of variables in the univariate analysis, only age, seasonal period, mechanical ventilation, continuous venovenous hemofiltration, and days until ICU admission were predictors of diagnostic delay in the logistic regression analysis. In our study there was a quite long interval between the day of blood sampling and the onset of treatment with oseltamivir even in the early diagnostic group, which may indicate that in most cases treatment was not started until the physician in charge was aware of positivity of influenza A (H1N1)pdm09 testing. Other reasons for late diagnosis, such as low degree of vigilance or false negative tests, were not recorded. Also, it has been shown that patients admitted to the ICU within the first 48 hours of hospitalization had a significantly lower severity level and mortality than those admitted to the ICU after 48 hours of hospitalization. According to these findings, a high level of clinical suspicion of influenza A (H1N1)pdm09 infection in patients at risk during flu outbreaks is needed, to establish the diagnosis as soon as possible and to reduce both delayed admission to the ICU and 
Table 1 Descriptive characteristics of patients admitted to the ICU with early or late diagnosis of influenza A (H1N1)pdm09 virus infection and independent factors related to diagnostic delay

\begin{tabular}{|c|c|c|c|c|c|}
\hline Variable & $\begin{array}{l}\text { Early diagnosis } \\
\text { ( } \leq 2 \text { days) }\end{array}$ & $\begin{array}{l}\text { Late diagnosis } \\
\text { (3-7 days) }\end{array}$ & $P$ value & $\begin{array}{l}\text { Odds ratio (95\% } \\
\text { confidence interval) }\end{array}$ & $P$ value \\
\hline Total patients & 1314 & 745 & & & \\
\hline Age (years), mean (SD) & $48.43(15.6)$ & $51.23(15.0)$ & 0.001 & $1.02(1.01-1.03)$ & 0.001 \\
\hline \multicolumn{6}{|l|}{ Sex } \\
\hline Men & $744(56.6)$ & $458(61.4)$ & 0.032 & & \\
\hline Women & $570(43.4)$ & $287(38.5)$ & & & \\
\hline \multicolumn{6}{|l|}{ Seasonal period } \\
\hline 2009-2012 & $732(59.45$ & $499(40.5)$ & 0.001 & $2.08(1.64-2.63)$ & 0.001 \\
\hline 2013-2015 & $582(70.3)$ & $246(29.7)$ & & & \\
\hline Influenza vaccine & $60(4.6)$ & $44(5.9)$ & 0.169 & & \\
\hline \multicolumn{6}{|l|}{ Comorbid conditions } \\
\hline Asthma & $148(11.3)$ & $72(9.7)$ & 0.262 & & \\
\hline Chronic obstructive pulmonary disease & $235(17.9)$ & $159(21.4)$ & 0.054 & & \\
\hline Heart failure & $122(9.3)$ & $84(11.3)$ & 0.146 & & \\
\hline Chronic renal failure & $81(6.2)$ & $69(9.2)$ & 0.013 & & \\
\hline Hematological disease & $66(5.0)$ & $64(8.6)$ & 0.001 & & \\
\hline Obesity & $459(34.9)$ & $269(36.1)$ & 0.574 & & \\
\hline Diabetes mellitus & $189(14.4)$ & $116(15.6)$ & 0.432 & & \\
\hline Human immunodeficiency virus infection & $32(2.4)$ & $15(2.0)$ & 0.540 & & \\
\hline Neuromuscular disease & $39(3.0)$ & $16(2.2)$ & 0.269 & & \\
\hline Autoimmune disease & $41(3.1)$ & $28(3.8)$ & 0.381 & & \\
\hline Immunosuppression & $105(8.0)$ & $102(13.7)$ & 0.001 & & \\
\hline Pregnancy & $53(4.0)$ & $29(3.9)$ & 0.879 & & \\
\hline APACHE II score, mean (SD) & $15(7)$ & $16(8)$ & 0.001 & & \\
\hline SOFA score, mean (SD) & $6(3)$ & $6(4)$ & 0.001 & & \\
\hline \multicolumn{6}{|l|}{ Presenting clinical manifestations } \\
\hline Primary viral pneumonia & $1129(85.9)$ & $603(81.0)$ & 0.004 & & \\
\hline Coinfection (bacterial pneumonia) & $219(16.7)$ & $133(17.9)$ & 0.458 & & \\
\hline Noninvasive mechanical ventilation & $482(36.67$ & $314(42.2)$ & 0.022 & & \\
\hline Mechanical ventilation & $864(65.0)$ & $569(76.4)$ & 0.001 & $1.58(1.17-2.13)$ & 0.002 \\
\hline Days on mechanical ventilation, median (IQR) & $8(2-15)$ & $9(4-20)$ & 0.001 & & \\
\hline Vasoactive drugs & $639(48.6)$ & $425(57.0)$ & 0.001 & & \\
\hline Decubitus prono & $233(17.7)$ & $143(19.52$ & 0.382 & & \\
\hline Continuous venovenous hemofiltration & $103(7.8)$ & $95(12.8)$ & 0.001 & $1.54(1.08-2.18)$ & 0.016 \\
\hline Corticoids & $527(40.1)$ & $335(45.0)$ & 0.043 & & \\
\hline Days on corticoids, median (IQR) & $7(4-10)$ & $7(5-12)$ & 0.071 & & \\
\hline Days until ICU admission, median (IQR) & $1(1-1)$ & $1(1-3)$ & 0.001 & $1.26(1.17-1.35)$ & 0.001 \\
\hline Length of ICU stay (days), median (IQR) & $8(4-17)$ & $10(5-20)$ & 0.001 & & \\
\hline Length of hospital stay (days), median (IQR) & $14(8-25)$ & $18(10-30)$ & 0.001 & & \\
\hline Days until oseltamivir therapy, median (IQR) & $4(2-6)$ & $5(3-7)$ & 0.001 & & \\
\hline Mortality rate & $225(17.1)$ & $200(26.9)$ & 0.001 & & \\
\hline
\end{tabular}

Data expressed as frequencies (percentages) unless otherwise stated

APACHE Acute Physiology and Chronic Health Evaluation, IQR interquartile range (25th-75th percentile), SD standard deviation, SOFA Sepsis-related Organ Failure Assessment 


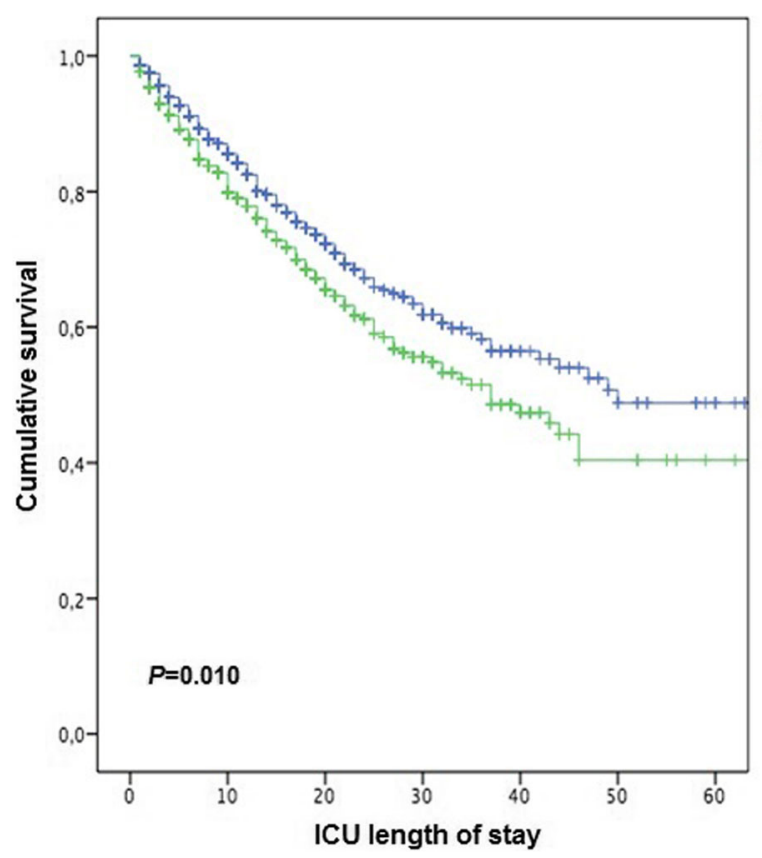

TIME OF DIAGNOSIS

48 hours

3 to 7 days

48 hours censored

3 to 7 days censored

Fig. 2 Kaplan-Meier survival curves for critically ill patients admitted to the ICU with confirmed influenza A (H1N1)pdm09 in the early and late diagnostic groups

specific treatment with oseltamivir. Patients at risk include nonvaccinated patients (which in our study have been most of the patients in both groups) and patients in whom vaccination is recommended.

The overall intra-ICU mortality was significantly higher in the late diagnosis group. The predicted mortality based on APACHE II score on ICU admission was higher $(22 \%)$ than the observed mortality $(17.1 \%)$ in the early diagnosis group, but lower in the late diagnosis group $(23.5 \%$ vs $26.9 \%)$. The reason why delay in diagnosis of influenza A (H1N1)pdm09 virus infection is associated with worse outcome is unclear, and a number of factors including a difference in days until oseltamivir therapy, delay in ICU admission, high severity of illness, some comorbidities, or other unidentified variables could have played a complementary role. Patients in the late diagnosis group showed higher APACHE II and SOFA scores on ICU admission, but data for severity of illness on hospital admission were not recorded, so it is unknown whether patients were already more severe on

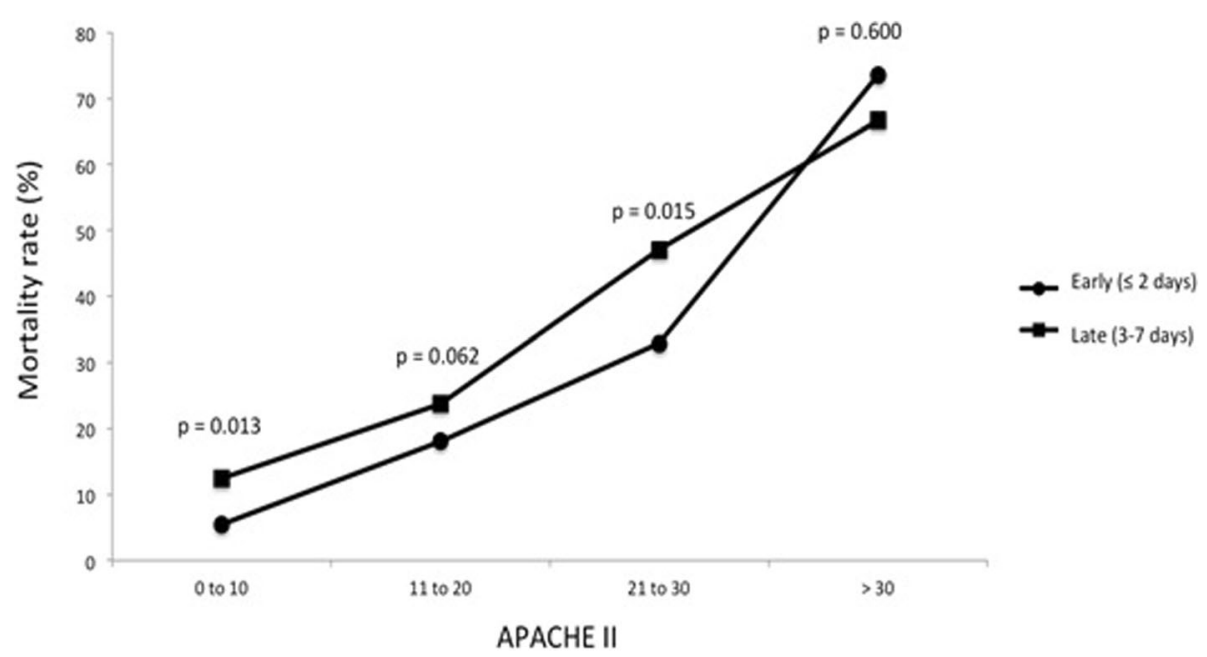

Fig. 3 Relationship between severity of illness on ICU admission (APACHE II score) and mortality in the early and late diagnosis of influenza A (H1N1)pdm09 virus infection. APACHE Acute Physiology and Chronic Health Evaluation 
Table 2 Patients diagnosed with influenza A (H1N1)pdm09 virus: differences between survivors and patients who died, and independent factors related to mortality

\begin{tabular}{|c|c|c|c|c|c|}
\hline Variable & Survivors & Patients who died & $P$ value & Odds ratio (95\% confidence interval) & $P$ value \\
\hline Total patients & 1528 & 395 & & & \\
\hline Age (years), mean (SD) & $48.32(15.24)$ & $53.08(15.51)$ & 0.001 & & \\
\hline \multicolumn{6}{|l|}{ Sex } \\
\hline Men & $865(56.6)$ & $255(64.6)$ & 0.004 & & \\
\hline Women & $662(43.4)$ & $140(35.4)$ & & & \\
\hline \multicolumn{6}{|l|}{ Seasonal period } \\
\hline 2009-2012 & $941(80.7)$ & $225(19.3)$ & 0.053 & & \\
\hline 2013-2015 & $587(77.5)$ & $170(22.5)$ & & & \\
\hline Influenza vaccine & $65(4.3)$ & $26(6.6)$ & 0.137 & & \\
\hline \multicolumn{6}{|l|}{ Comorbid conditions } \\
\hline Asthma & $113(11.6)$ & $18(6.6)$ & 0.019 & & \\
\hline Chronic obstructive pulmonary disease & $291(19.0)$ & $73(18.5)$ & 0.824 & & \\
\hline Heart failure & $140(9.2))$ & $53(13.4)$ & 0.011 & & \\
\hline Chronic renal failure & $82(5.4)$ & $53(13.4)$ & 0.001 & & \\
\hline Hematological disease & $65(4.3)$ & $52(13.2)$ & 0.001 & $1.98(1.23-3.19)$ & 0.001 \\
\hline Obesity & $523(34.2)$ & $139(35.2)$ & 0.683 & & \\
\hline Diabetes mellitus & $212(13.9)$ & $65(16.5)$ & 0.183 & & \\
\hline Human immunodeficiency virus infection & $26(1.7)$ & $17(4.3)$ & 0.002 & & \\
\hline Neuromuscular disease & $44(2.9)$ & $11(2.8)$ & 0.929 & & \\
\hline Autoimmune disease & $45(2.9)$ & $20(5.1)$ & 0.036 & & \\
\hline Immunosuppression & $99(6.5)$ & $89(22.5)$ & 0.001 & & \\
\hline Pregnancy & $64(4.2)$ & $11(2.8)$ & 0.203 & & \\
\hline APACHE II score, mean (SD) & $14(6)$ & $21(8)$ & 0.001 & $1.09(1.07-1.11)$ & 0.001 \\
\hline SOFA score, mean (SD) & $5(3)$ & $8(4)$ & 0.001 & & \\
\hline \multicolumn{6}{|l|}{ Presenting clinical manifestations } \\
\hline Primary viral pneumonia & $1273(83.3)$ & $342(86.6)$ & 0.105 & & \\
\hline Coinfection (bacterial pneumonia) & $229(15.0)$ & $96(24.3)$ & 0.001 & & \\
\hline Noninvasive mechanical ventilation & $527(34.75$ & $141(35.7)$ & 0.330 & & \\
\hline Mechanical ventilation & $812(53.1)$ & $366(92.7)$ & 0.001 & $4.84(2.73-8.56)$ & 0.001 \\
\hline Vasoactive drugs & $664(43.5)$ & $307(77.7)$ & 0.001 & & \\
\hline Decubitus prono & $206(13.05$ & $133(33.7)$ & 0.001 & & \\
\hline Continuous venovenous hemofiltration & $67(4.4)$ & $116(29.4)$ & 0.001 & $4.81(3.31-7.01)$ & 0.001 \\
\hline Corticoids & $500(32.7)$ & $196(49.6)$ & 0,001 & & \\
\hline Days until ICU admission, median (IQR) & $1(1-2)$ & $1(1-3)$ & 0.001 & $1.05(0.99-1.11)$ & 0.117 \\
\hline Length of ICU stay (days), median (IQR) & $8(4-18)$ & $9(4-18)$ & 0.660 & & \\
\hline Length of hospital stay (days), median (IQR) & $16(10-30)$ & $11(5-21)$ & 0.001 & & \\
\hline Days until oseltamivir therapy, median (IQR) & $4(2-6)$ & $5(3-6)$ & 0.054 & & \\
\hline \multicolumn{6}{|l|}{ Time of diagnosis } \\
\hline Early ( $\leq 2$ days) & $1035(67.7)$ & $214(54.2)$ & 0.001 & $1.36(1.03-1.81)$ & 0.001 \\
\hline Late (3-7 days) & 493 (32.3) & $181(45.8)$ & & & \\
\hline
\end{tabular}

Data expressed as frequencies (percentages) unless otherwise stated

APACHE Acute Physiology and Chronic Health Evaluation, IQR interquartile range (25th-75th percentile), SD standard deviation, SOFA Sepsis-related Organ Failure Assessment 
hospital admission or worsened during hospitalization due to lack of an early diagnosis, appropriate treatment, or prompt ICU admission. Up to the present time, a number of factors related with mortality in patients diagnosed with influenza A (H1N1)pdm09 virus infection have been reported, including age, severity of illness on admission, underlying immunosuppression, delay in starting specific antiviral treatment (oseltamivir), duration of symptoms before the initiation of treatment, presence of hematological or cardiac disease, need for mechanical ventilation or extrarenal depuration techniques, and dyspnea or signs of alteration of the central nervous system on admission, among others. The present study provides the first observation that a delay in the diagnosis of influenza A (H1N1)pdm09 may be an independent factor associated with a higher mortality rate. Our data are complementary to other observations in which mortality is related with a delay in starting antiviral treatment and a greater duration of clinical signs of infection prior to diagnosis of infection by influenza A (H1N1)pdm09 virus [20]. For this reason, in critically ill patients admitted to the ICU and because of the increase in mortality associated with a delay in diagnosis, it is recommended to initiate antiviral treatment on diagnostic suspicion [32, 33].

Some limitations of the study should be taken into account. Firstly, the classification used for defining early and late diagnosis is based on epidemiological and microbiological considerations (viral shedding time) upon which there is no consensus in the literature. The selection of 48 hours was arbitrary. Considering that the criterion to define the time of diagnosis of influenza $\mathrm{A}$ was the day of blood sampling that allowed the identification of infection, and because this technique is not available in the emergency laboratories of some Spanish hospitals, 48 hours was assumed as the cutoff point given that in many centers a sample for PCR assay was electively collected on the next day of admission to the emergency department. However, a further analysis with early diagnosis at $\leq 24$ hours and late diagnosis at 2-7 days showed similar results (data not shown). Differences in clinical characteristics and outcome between patients in the early and late diagnostic groups emphasize the need for including this classification to homogenize risk groups in future studies. On the other hand, retrospective analysis of an epidemiological prospective database prevents the inclusion of new variables that might have been of help to define the proposed classification. The multicenter design of the study in which a therapeutic protocol has not been established previously may be associated with treatment bias, given that treatments considered most adequate were those used by each participating group. Moreover, certain variability in the interpretation of clinical signs might be present, although consensuated definitions were used for most study variables.

\section{Conclusions}

This study shows important differences in patients diagnosed with influenza A (H1N1)pdm09 virus infection depending on the speed with which the infection is diagnosed. Late diagnosis of community-acquired influenza A (H1N1)pdm09 infection is associated with a higher severity of illness, delay in ICU admission, need for therapeutic resources, greater duration of ICU and hospital stay, and, more importantly, higher intra-ICU mortality. The present findings highlight the need during the epidemiological seasons for an early diagnosis of influenza A (H1N1)pdm09 and prompt antiviral treatment in all hospitalized patients with signs of respiratory infection, independently of other clinical diagnoses.

\section{Abbreviations \\ APACHE II: Acute Physiology and Chronic Health Evaluation; CDC: Centers for Disease Control and Prevention; Cl: Confidence interval; GETGAG: Spanish Working Group on Severe Pandemic Influenza A; HIV: Human immunodeficiency virus; ICU: Intensive care unit; OR: Odds ratio; rt-PCR: Real-time polymerase chain reaction; SEMICYUC: Spanish Society of Critical Care Medicine and Coronary Units; SOFA: Sepsis-related Organ Failure Assessment}

\section{Acknowledgements}

This article was presented at the LI Annual Congress of the SEMICYUC, Valencia, Spain, June 19-22, 2016 and at the 29th European Society of Intensive Care Medicine (ESCIM), Milan, Italy, October 14, 2016 (abstract accepted)

The authors thank all healthcare personnel involved in the care of patients with influenza A (H1N1)pdm09 virus infection during their stay in the ICU and who endeavored to follow the recommendations to reduce transmission of influenza A infection. They are indebted to physicians responsible for entering data into the GETGAG/SEMICYUC registry for their valuable collaboration, and Marta Pulido, MD, for editing the manuscript and editorial assistance. The fees for medical editing were paid by Fundació IMIM, Barcelona, Spain.

H1N1 GETGAG/SEMICYUC Study Group (alphabetical order by Autonomous Community):

Andalucía

Pedro Cobo (Hospital Punta de Europa, Algeciras); Javier Martins (Hospital Santa Ana Motril, Granada); Cecilia Carbayo (Hospital Torrecárdenas, Almería); Emilio Robles-Musso, Antonio Cárdenas, and Javier Fierro (Hospital del Poniente, Almería); Dolores Ocaña Fernández (Hospital Huercal-Overa, Almería); Rafael Sierra (Hospital Puerta del Mar, Cádiz); Ma Jesús Huertos and Ma Luz Carmona Pérez (Hospital Puerto Real, Cádiz); Juan Carlos Pozo Laderas, R. Guerrero, Juan Carlos Robles, Melissa Echevarría León, and Alberto Bermejo Gómez (Hospital Reina Sofía, Córdoba); Enrique Márquez (Hospital Infanta Elena, Huelva); Manuel Rodríguez-Carvajal (Hospital Juan Ramón Jiménez, Huelva); Ángel Estella (Hospital del SAS de Jerez, Jerez de la Frontera); José Pomares, José Luis Ballesteros, and Olga Moreno Romero (Hospital Universitario San Cecilio, Granada); Yolanda Fernández, Francisco Lobato, José F. Prieto, and José Albofedo-Sánchez (Hospital Costa del Sol, Marbella, Málaga); Pilar Martínez, María Victoria de la Torre, María Nieto, and Estefanía Cámara Sola (Hospital Vírgen de la Victoria, Málaga); Miguel Ángel Díaz Castellanos (Hospital Santa Ana de Motril, Granada); Guillermo Sevilla Soler and Carlos Ortiz Leyba (Clínica Sagrado Corazón, Sevilla); José Garnacho-Montero, Rafael Hinojosa, and Esteban Fernández (Hospital Universitario Virgen del Rocío, Sevilla); Ana Loza, Cristóbal León, and Samuel González López (Hospital Universitario Nuestra Señora de Valme, Sevilla); Ángel Arenzana (Hospital Virgen de la Macarena, Sevilla); Dolores Ocaña (Hospital de la Inmaculada, Sevilla); Inés Navarrete (Hospital Virgen de las Nieves, Granada); Medhi Zaheri Beryanaki (Hospital de Antequera, Málaga); Ignacio Sánchez and Manuel Pérez Alé (Hospital Nisa Sevilla Aljarafe, Sevilla); 
Ana Ma Poullet Brea (Hospital Quirón Málaga, Málaga); and Juan Francisco Machado Casas (Complejo Hospitalario de Jaén, Jaén).

\section{Aragón}

Carlos Serón, Manuel Luis Avellanas, Arantxa Lander, S. Garrido Ramírez de Arellano, and M.I. Marquina Lacueva (Hospital San Jorge, Huesca); Pilar Luque, Elena Plumed Serrano, Juan Francisco Martín Lázaro, Carlos Sánchez Polo, Isabel Gutiérrez Cía, Belén Jiménez Bartolomé, and Carlos López Núñez (Hospital Clínico Universitario Lozano Blesa, Zaragoza); Ignacio González, José Ignacio Tomás Marsilla, Clara Jaques Andrés, Pablo Gutiérrez Ibañes, and Pilar Araujo Aguilar (Hospital Universitario Miquel Servet, Zaragoza); Jose Ma Montón (Hospital Obispo Polanco, Teruel); and Paloma Dorado Regil (Hospital Royo Villanova, Zaragoza). Asturias

Lisardo Iglesias, Carmen Pascual González, Brígida Quindós Fernández, Lorena Martín Iglesias, Lucía Viña Soria, Raquel Yano Escudero, and Ma del Rosario Martínez Revuelta (Hospital Universitario Central de Asturias, Oviedo); José Ma Quiroga Ruiz (Hospital de Cabueñes, Gijón); Águeda García-Rodríguez (Hospital Valle del Nalón, Langreo); and Marta Martín Cuadrado and Ana Luz Balán Mariño (Hospital San Agustín, Avilés).

\section{Baleares}

Lorenzo Socias, Pedro Ibáñez, Marcío Borges-Sa, A. Socias and A. Del Castillo (Hospital Son Llàtzer, Palma de Mallorca); Ricard Jordà Marcos and Cristina Muñoz (Clínica Rotger, Palma de Mallorca); José M. Bonell Goytisolo and José Antonio Morales Carbonero (Hospital Quiròn Salud Palmaplanas, Palma de Mallorca); Ignacio Ayestarán (Hospital Son Dureta, Palma de Mallorca); M. Ángeles González López and Cecilia Vilanova Pàmies (Hospital Mateu Orfila, Palma de Mallorca); and Rossana Pérez Senoff and Marta Generelo López de Medrano (Hospital Comarcal de Inca, Palma de Mallorca).

\section{Canarias}

Sergio Ruiz-Santana, Juan José Díaz, and Catalina Sánchez Ramírez (Hospital Universitario de Gran Canaria Dr. Negrín, Las Palmas de Gran Canaria); Montse Sisón (Hospital Doctor José Molina, Lanzarote); David Hernández, Ana Trujillo, Luis Regalado, and Sonia Rodríguez Fernández (Hospital General la Palma, La Palma); Leonardo Lorente, Judith Cabrera Rivero, and $\mathrm{M}^{\mathrm{a}}$ Luisa Mora Quintero (Hospital Universitario de Canarias, Tenerife); Mar Martín (Hospital de la Candelaria, Tenerife); Sergio Martínez, J.J. Cáceres, and Manuel Sánchez Palacio (Hospital Insular de Gran Canaria); and D. García Rodríguez and María Ripoll Leria (Hospital General de Fuerteventura, Fuerteventura)

\section{Cantabria}

Borja Suberviola and P. Ugarte (Hospital Universitario Marqués de Valdecilla, Santander).

\section{Castilla La Mancha}

Fernando García-López and Rafael Sánchez Iniesta (Hospital General, Albacete); Ángel Álvaro Alonso, Antonio Padilla, and Basi Martínez Palacios (Hospital General La Mancha Centro, Alcázar de San Juan); Ma Luisa Gómez Grande, Ma Carmen Martín Rodríguez, Hasania Adbel-Hadi Álvarez, Alfonso Ambros Checa, and Higinio Martín Hernández (Hospital General de Ciudad Real, Ciudad Real); Antonio Albaya, Alberto Silva Obregón, Carlos Marian Crespo, Carlos Armendáriz Estrella, Carmen Benito Puncel, and Eduardo Quirós Oyargue (Hospital Universitario de Guadalajara, Guadalajara); Alfonso Canabal, Luis Marina, and Ismael López de Toro (Hospital Virgen de la Salud, Toledo); Almudena Simón (Hospital Nuestra Señora del Prado, Toledo); and José María Añón (Hospital Virgen de la Luz, Cuenca).

\section{Castilla y León}

Ma Jesús López Pueyo, María del Valle Ortiz, and Sergio Ossa Echeverri (Hospital General Yagüe, Burgos); Zulema Ferreras and Juan C. Ballesteros Herraez (Hospital Universitario de Salamanca, Salamanca); Santiago Macías (Hospital General de Segovia, Segovia); José Ángel Berezo, Jesús Blanco Varela, Pablo Blanco Schweizer, Ángela González Salamanca, and Luis Tamayo Lomas (Hospital Universitario Río Hortega, Valladolid); Andaluz Ojeda Anzález, Ramón Cicuéndez Ávila, and Francisco Javier Pérez G (Hospital Universitario, Valladolid); Antonio Álvarez Terrero (Hospital Virgen de la Concha, Zamora); Fabiola Tena Ezpeleta, Christian Sala, and Oliverio López (Hospital Santa Bárbara, Soria); Zulema Páez and Álvaro García (Hospital Virgen de la Vega, Salamanca); Demetrio Carriedo Ule and Miriam Riesco Crespo (Complejo Asistencial Universitario de León-CAULE, León); Jesús Pino Rebolledo and Nicolás Hidalgo Andrés (Hospital Campo Grande, Valladolid); Ana Carolina Caballero Zirena (Complejo Asistencial de Zamora, Zamora); Belén Román García and Juan Bautista López Messa (Hospital General Río Carrión, Palencia).

\section{Catalunya}

Rosa Ma Catalán (Hospital General de Vic, Vic, Barcelona); Miquel Ferrer, Antoni Torres, and Catia Cilloniz (Hospital Clínic, Barcelona); Sandra Barbadillo Ansorregui (Hospital General de Catalunya-Capio, Sant Cugat del Vallés, Barcelona); Lluís Cabré and Ignacio Baeza (Hospital de Barcelona, Barcelona); Assumpta Rovira (Hospital General de l'Hospitalet, L'Hospitalet de Llobregat, Barcelona); Francisco Álvarez-Lerma, Antonia Vázquez, and Joan Nolla (Hospital del Mar,Barcelona); Francisco Fernández, Joaquim Ramón Cervelló, and Raquel Iglesia (Centro Médico Delfos, Barcelona); Rafael Mañéz, J. Ballús, and Rosa Ma Granada (Hospital Universitari de Bellvitge, L'Hospitalet de Llobregat, Barcelona); Jordi Vallés, Emili Díaz, Marta Ortíz, C. Guía, and Ignacio Martín-Loeches (Hospital de Sabadell, Sabadell, Barcelona); Joaquim Páez (Hospital Dos De Mayo, Barcelona); Jordi Almirall, Xavier Balanzó, Estel Güell, and Juan Carlos Yébenes (Hospital de Mataró, Mataró, Barcelona); Jordi Rello, Elena Arnau, Marcos Pérez, César Laborda, Jesica Souto, and Leonel Lagunes (Hospital Universitari Vall d'Hebron, Barcelona); Iñaki Catalán (Hospital Sant Joan de Déu, Manresa); Josep Ma Sirvent, Nerea López de Arbina, Anna Baró Serra, Adriana Sánchez, and Silvia M. Cuenca (Hospital Josep Trueta, Girona); Mariona Badía, Begonia Baseda-Garrido, Montserrat Valverdú-Vidal, Fernando Barcenilla, Mercedes Palomar, and Xavier Nuvials (Hospital Universitari Arnau de Vilanova, Lleida); Pedro Garrido Benedicto (Hospital Sant Joan de Reus, Reus, Tarragona); Ferrán Roche Campo, M.F. Esteban, José Luna, Gaspar Masdeu Eixarch, and Angels Pascual Diago (Hospital Verge de la Cinta, Tortosa, Tarragona); Juan Ma Nava, J. González de Molina, Josep Trenado, and Ricard Ferrer (Hospital Universitari Mútua de Terrassa, Terrassa, Barcelona); Zoran Josic and Montserrat Casanovas (Hospital de Igualada, Igualada, Barcelona); Francisco Gurri and Paula Rodríguez (Hospital Quirón, Barcelona); Alejandro Rodríguez, Laura Claverías, Sandra Trefler, María Bodí, Mónica Magret, and Cristina Ferri (Hospital Universitario Joan XXIII, Tarragona); Rosa María Díaz (Hospital San Camil, Sant Pere de Ribes, Barcelona); Eduard Mesalles and Fernando Arméstar (Hospital Universitari GermansTrias i Pujol, Badalona, Barcelona); Diego de Mendoza, Carmen Lomas Fernández, and José Julián Berrade (Hospital Miquel Broggi, Sant Joan Despí, Barcelona); Alfonso Bonet Saris and Marina Pechkova (Clínica Girona, Girona); Cristina Mora Jiménez (Hospital del Sagrat Cor, Barcelona); and Santiago Picos Gil (Clínica Diagonal, Barcelona).

\section{Extremadura}

Juliá-Narváez José, Manuel Robles Marcos, Vanessa Farje Mallqui, Ma Ángeles Santiago Triviño, and Pablo Martínez García (Hospital Infanta Cristina, Badajoz); Alberto Fernández-Zapata, Teresa Recio, Abilio Arrascaeta, Ma José García-Ramos, Elena Gallego, and Esther Saiz Rodrigo (Hospital San Pedro de Alcántara, Cáceres); Fernando Bueno (Hospital Virgen del Puerto, Plasencia, Cáceres); Mercedes Díaz, Noemí Gil Pérez, and David López Hormigo (Hospital de Mérida, Mérida); Juan Diego Jiménez Delgado (Hospital Don Benito, Villanueva de la Serena, Badajoz); Pérez Frutos and M.J. Rivera Pinna (Hospital Perpetuo Socorro, Badajoz).

\section{Galicia}

Ma Lourdes Cordero, José A. Pastor, Luis Álvarez-Rocha, Alexandra Ceniceros Barros, and Alejandra Virgós Pedreira (Complexo Hospitalario Universitario A Coruña, A Coruña); Dolores Vila (Hospital Do Meixoeiro, Vigo); Carmen Fernández González (Complexo Hospitalario Universitario de Ferrol, Ferrol, A Coruña); Eleuterio Merayo, Víctor José López-Ciudad, Juan Cortés Cañones, Eva Vilaboy, José Villar Chao, Francisco Savira Cid López, Pablo Vidal Cortés, and Marcos A. Pérez Veloso (Complejo Hospitalario de Ourense, Ourense); Eva María Saborido, Enrique Alemparte Pardavila, and Ana Ortega Montes (Hospital Montecelo, Pontevedra); Raúl José González (Hospital Miguel Domínguez, Pontevedra); Santiago Freita, Enrique Alemparte, and Ana Ortega (Complejo Hospitalario de Pontevedra, Pontevedra); Ana María López, Julio Canabal, and Enrique Ferres (Clínica Universitaria Santiago de Compostela, Santiago de Compostela, A Coruña); Javier Blanco Pérez and M. Ortiz Piquer (Hospital Lucus Augusti-HULA, Lugo); Santiago Freitas Ramos, Lucas Lage Cendón, Vanesa Gómez Casal, Sabela Vara Adrio, Eva Menor Fernández, and Susana González Prado (H. Xeral-C.H.U. de Vigo, Vigo); and Antonio Varela Franco (Hospital Vithas Nuestra Señora de Fátima, Vigo). La Rioja José Luis Monzón and Félix Goñi (Hospital San Pedro, Logroño). Madrid

Frutos Del Nogal Sáez, M. Blasco Navalpotro, Ricardo Díaz Abad, and José Luis Flordelis Lasierra (Hospital Severo Ochoa, Madrid); Ma Carmen GarcíaTorrejón (Hospital Infanta Elena, Madrid); César Pérez-Calvo and Diego López (Fundación Jiménez Díaz, Madrid); Luis Arnaiz, S. Sánchez-Alonso, and Carlos 
Velayos (Hospital Fuenlabrada, Fuenlabrada, Madrid); Francisco del Río, Miguel Ángel González, Mercedes Nieto, and Carmen Sánchez Cesteros (Hospital Clínico San Carlos, Madrid); María Cruz Martín and José Ma Molina (Hospital Nuestra Señora de América, Madrid); Juan Carlos Montejo and Mercedes Catalán (Hospital Universitario 12 de Octubre, Madrid); Patricia Albert and Ana de Pablo (Hospital del Sureste, Arganda del Rey, Madrid); José Eugenio Guerrero, María Zurita, Jaime Benítez Peyrat, and Miriam Díaz Cámara (Hospital Universitario Gregorio Marañón, Madrid); Enrique Cerdá, Manuel Alvarez, Carlos Pey, Eva Manteiga Riestra, and Concepción MartínezFidalgo (Hospital Infanta Cristina, Parla, Madrid); Montse Rodríguez and Eduardo Palencia (Hospital Infanta Leonor, Madrid); Rafael Caballero (Hospital de San Rafael, Madrid); Concepción Vaquero, Francisco Mariscal, S. García, and Rico Cepeda (Hospital Infanta Sofía, Madrid); Nieves Carrasco (Hospital Universitario La Princesa, Madrid); Isidro Prieto, A Liétor, R. Ramos, Rosario Cuadra Casas, Cruz Soriano Cuesta, and Susana Sánchez Alonso (Hospital Ramón y Cajal, Madrid); Beatriz Galván, Juan C. Figueira, M. Cruz Soriano, Belen Civantos Martín, and Alejandro Robles Caballero (Hospital La Paz, Madrid); P. Galdós, Bárbara Balandín Moreno, and Sara Alcántara Carmona (Hospital Puerta de Hierro, Madrid); Fernández del Cabo (Hospital Monte Príncipe, Madrid); Cecilia Hermosa and Federico Gordo (Hospital de Henares, Madrid); Alejandro Algora (Hospital Universitario Fundación Alcorcón, Madrid); Amparo Paredes and Teodoro Grau Carmona (Hospital Sur de Alcorcón, Madrid); J.A. Cambronero, Esther López Ramos, and Yaiza Ortiz de Zárate (Hospital Universitario Príncipe de Asturias, Madrid); Sonia Gómez-Rosado, Margarita Mas Lodo, Nieves Franco Garrobo, Silvia Álvarez Hernández, and Teresa Honrubia (Hospital de Móstoles, Madrid); Luis Miguel Prado López (Hospital Sanitas La Zarzuela, Madrid); Esteban A. Lorente, J.A. Nin, and Carlos Jaramillo Sotomayor (Hospital de Getafe, Madrid); Luis Arnaiz (Sanitas de Moraleja, Madrid); Esperanza Molero Silvero and Eduardo Morales Fernández de la Reguera (Hospital Central de la Defensa "Gómez Ulla", Madrid); Rosa Ma de la Casa Monje and Fátima Martín Serrano (Clínica Moncloa, Madrid); and Ma Victoria Trasmonte Martínez, and M. Cruz Martín Delgado (Hospital de Torrejón, Torrejón de Ardoz, Madrid).

\section{Murcia}

Sofía Martínez (Hospital Santa María del Rosell, Murcia); F. Felices Abad, Isabel Cremades Navalon, and Martín Vigil Velis (Hospital Universitario Reina Sofía, Murcia); Mariano Martínez, Domingo Martínez Baño, and Enriqueta Andreu (Hospital Universitario Virgen de la Arrixaca, Murcia); Sergio Manuel Butí, Bernardo Gil Rueda, and Francisco García (Hospital Morales Messeguer, Murcia); Noemí Llamas Fernández (Hospital General Universitario Rafael Méndez, Lorca); Luis Herrera Para and Alejandro Ortín Freire (Hospital Universitario Santa Lucía, Cartagena); and Ma Rosa Navarro Ruiz and C.R. Hernández Romero (Hospital Los Arcos del Mar Menor, Murcia).

\section{Navarra}

Enrique Maraví-Poma, I. Jimenez Urra, Laura Macaya Redin, and A. Tellería (Hospital Virgen del Camino, Pamplona); Josu Insausti (Hospital de Navarra, Pamplona); and Noelia Artesero García, Laura Macaya, and Joaquín Lobo Palanco (Complejo Hospitalario de Navarra, Pamplona).

\section{País Vasco}

Nagore González, Pilar Marco, Loreto Vidaur, Estibaliz Salas, and Ruth Salaberría Udabe (Hospital Universitario Donostia, San Sebastián-Donostia); B. Santamaría and Tomás Rodríguez (Hospital de Basurto, Bilbao); Juan Carlos Vergara, Jose Ramón Iruretagoyena Amiano, and Iratí Garrido Santos (Hospital de Cruces, Barakaldo, Bizkaia); Alberto Manzano (Hospital Santiago Apóstol, Vitoria-Gasteiz); Carlos Castillo Arenal (Hospital Txagorritxu, VitoriaGasteiz); Pedro María Olaechea and Higinio Martín Hernández (Hospital de Galdakao, Usansolo, Bizkaia); and Alejandro Martín López and Fernando Fonseca San Miguel (Hospital Universitario de Álava-Santiago, Vitoria-Gasteiz). Valencia

José Blanquer, Nieves Carbonell, and José Ferreres Franco (Hospital Clinic Universitari, Valencia); Roberto Reig Valero, A. Belenger, and Susana Altaba (Hospital General de Castellón, Castellón); Bernabé Âlvarez-Sánchez, José Cánovas Robles, Jaime Sánchez Francisco, and Mar Ruiz Sánchez (Hospital General de Alicante, Alicante); Santiago Alberto Picos, Abilio Arrascaeta Llanes, Eugenio Herrero Gutiérrez, and Alberto Fernández Zapata (Hospital Torrevieja Salud, Alicante); Ángel Sánchez-Miralles and José Luis Antón Pascual (Hospital San Juan, Alicante); Juan Bonastre, M. Palamo, Javier Cebrián, José Cuñat, and Mónica Gordón Sahuquillo (Hospital Universitari i Politècnic La Fe, Valencia); Belén Romero, Santiago Borrás Pallé, and Javier de León Belmar (Hospital de Manises, Valencia); Rafael Zaragoza, Constantino Tormo, and Susana Sancho Chinesta (Hospital Universitari Doctor Peset,
Valencia); Virgilio Paricio (Hospital de Requena, Valencia); Asunción Marqués, S. Sánchez-Morcillo, and S. Tormo (Hospital de la Ribera, Valencia); J. Latour (Hospital General Universitario de Elche, Valencia); M. Ángel García and Manuel Palomo (Hospital de Sagunto, Castellón); Francisco Tarín Royo and Pedro Manzano Hinojosa (Hospital de Denia, Alicante); Ma Salomé Sánchez Pino (Hospital Vega Baja, Alicante); and Concha Maragues Ribes and Rubén González Luis (Hospital de la Plana, Castellón).

Antolí Ribas from Hospital Nuestra Señora de Meritxell (Andorra) was also a member of the group.

\section{Funding}

The registry for patients with influenza $A$ has been developed by the GETGAG and is owned by the SEMICYUC (GETGAG/SEMICYUC).

\section{Authors' contributions}

$F A-L$ participated in the study conception and design, data collection, and interpretation of analysis and drafted the manuscript. JM-C participated in the study conception and design, statistical analysis and interpretation, and critical review of the manuscript for intellectual content. CV participated in data collection and revised the manuscript. JRM participated in data collection and helped to revise the manuscript. FJGdM participated in data collection and helped to revise the manuscript. IML participated in the design of the database, helped in data collection, and helped to revise the manuscript. SB participated in data collection and helped to revise the manuscript. AR participated in the study design and coordination, helped to design the database, and carried out the collection of data. All authors read and approved the final manuscript.

\section{Competing interests}

The authors declare that they have no competing interests.

\section{Consent for publication}

Not applicable.

\section{Ethics approval and consent to participate}

The study was approved by the Institutional Review Board of University Hospital Joan XXIII of Tarragona, Spain. Consent statement is not applicable given the noninterventional nature of the study because data were collected retrospectively from the GETGAG/SEMICYUC registry.

\section{Accession number to microarray data}

Not applicable.

\author{
Author details \\ ${ }^{1}$ Service of Intensive Care Medicine, Hospital del Mar, Passeig Marítim 25-29, \\ E-08003 Barcelona, Spain. ${ }^{2}$ Research Group in Critical Disorders (GREPAC), \\ Institut Hospital del Mar d'Investigacions Mèdiques (IMIM), Barcelona, Spain. \\ ${ }^{3}$ Universitat Autónoma de Barcelona, Barcelona, Spain. ${ }^{4} \mathrm{CIBER}$ de \\ Enfermedades Respiratorias (CIBERES), Madrid, Spain. ${ }^{5}$ Universitat Pompeu \\ Fabra, Barcelona, Spain. ${ }^{6}$ Service of Intensive Care Medicine, Hospital \\ Universitari Mútua de Terrassa, Terrassa, Barcelona, Spain. ${ }^{7}$ Service of \\ Intensive Care Medicine, St James Hospital, Dublin, Ireland. ${ }^{8}$ Service of \\ Intensive Care Medicine, Hospital General de Catalunya, Sant Cugat del \\ Vallés, Barcelona, Spain. ${ }^{9}$ Service of Intensive Care Medicine, Hospital \\ Universitari Joan XXIII, IISPV-URV, Tarragona, Spain.
}

\section{Received: 21 July 2016 Accepted: 26 September 2016} Published online: 23 October 2016

\section{References}

1. Pérez-Carrasco M, Lagunes L, Antón A, Gattarello S, Laborda C, Pumarola C, et al. Influenza infection in the intensive care unit: four years after the 2009 pandemic. Enferm Infecc Microbiol Clin. 2016;34:177-83.

2. Streng A, Prifert C, Weissbrich B, Liese JG, Bavarian PICU Study Group on Influenza and Other Viral ARI. Continued high incidence of children with severe influenza $A(\mathrm{H} 1 \mathrm{~N} 1)$ pdm09 admitted to paediatric intensive care units in Germany during the first three post-pandemic influenza seasons, 2010/ 11-2012/13. BMC Infect Dis. 2015;15:573. doi:10.1186/s12879-015-1293-1.

3. Puskarich MA, Trzeciak S, Shapiro NI, Arnold RC, Horton JM, Studnek JR, Emergency Medicine Shock Research Network (EMSHOCKNET), et al. Association between timing of antibiotic administration and mortality from 
septic shock in patients treated with a quantitative resuscitation protocol. Crit Care Med. 2011;39:2066-71.

4. Dellinger RP, Levy MM, Rhodes A, Annane D, Gerlach H, Opal SM. Surviving Sepsis Campaign Guidelines Committee including the Pediatric Subgroup, et al. Surviving sepsis campaign: international guidelines for management of severe sepsis and septic shock: 2012. Crit Care Med. 2013;41:580-637.

5. Ferrer R, Martin-Loeches I, Phillips G, Osborn TM, Townsend S, Dellinger RP, et al. Empiric antibiotic treatment reduces mortality in severe sepsis and septic shock from the first hour: results from a guideline-based performance improvement program. Crit Care Med. 2014;42:1749-55.

6. Sterling SA, Miller WR, Pryor J, Puskarich MA, Jones AE. The impact of timing of antibiotics on outcomes in severe sepsis and septic shock: a systematic review and meta-analysis. Crit Care Med. 2015;43:1907-15.

7. Rello J, Rodríguez A, Ibañez P, Socias L, Cebrian J, Marques A, Guerrero J, Ruiz-Santana S, et al. Intensive care adult patients with severe respiratory failure caused by influenza A (H1N1)V in Spain. Crit Care. 2009;13(5):R148.

8. Rodríguez A, Sirvent JM, Socias L, Martínez-Cuellar S, Rello J. Real-time reverse-transcription $P C R$ in the diagnosis of influenza $A(H 1 N 1) V$ in intensive care unit adult patients. Crit Care. 2009;13:428.

9. Zhang PJ, Cao B, Li XL, Liang LR, Yang SG, Gu L, et al. Risk factors for adult death due to 2009 pandemic influenza A (H1N1) virus infection: A 2151 severe and critical cases analysis. Chin Med J (Engl). 2013;126:2222-8.

10. Lynfield R, Davey R, Dwyer DE, Losso MH, Wentworth D, Cozzi-Lepri A, INSIGHT, INSIGHT. Influenza Study Group, et al. Outcomes of influenza A(H1N1)pdm09 virus infection: results from two international cohort studies. PLoSOne. 2014;9:e101785.

11. Garnacho-Montero J, Gutiérrez-Pizarraya A, Márquez JA, Zaragoza R, Granada R, Ruiz-Santana S, et al. Epidemiology, clinical features, and prognosis of elderly adults with severe forms of influenza A (H1N1). J Am Geriatr Soc. 2013;61:350-6.

12. Fezeu L, Julia C, Henegar A, Bitu J, Hu FB, Grobbee DE, et al. Obesity is associated with higher risk of intensive care unit admission and death in influenza A (H1N1) patients: a systematic review and meta-analysis. Obes Rev. 2011;12:653-9.

13. López-Aldeguer J, Iribarren JA, Valencia E, Barquilla E, Knobel H, Santos J, et al. Outcomes in HIV-infected patients admitted due to pandemic influenza. Enferm Infecc Microbiol Clin. 2012;30:608-12.

14. Bal CK, Bhatia V, Kumar S, Saini D, Khillan V, Gupta E, et al. Influenza A/H1/ N1/09 infection in patients with cirrhosis has a poor outcome: a case series. Indian J Gastroenterol. 2014;33:178-82.

15. Hernández-Bou S, Novell CB, Alins JG, García-García JJ. Hospitalized children with influenza A H1N1 (2009) infection: a Spanish multicenter study. Pediatr Emerg Care. 2013;29:49-52.

16. Maraví-Poma E, Martin-Loeches I, Regidor E, Laplaza C, Cambra K, Aldunate S. Severe 2009 A/H1N1v influenza in pregnant women in Spain. Crit Care Med. 2011:39:945-51.

17. Martin-Loeches I, Díaz E, Vidaur L, Torres A, Laborda C, Granada R, et al. Pandemic and post-pandemic influenza A ( $\mathrm{H} 1 \mathrm{~N} 1)$ infection in critically ill patients. Crit Care. 2011;15:R286.

18. Rodríguez A, Martin-Loeches I, Bonastre J, Olaechea P, Álvarez-Lerma F, Zaragoza R, et al. First influenza season after the 2009 pandemic influenza: report of the first $300 \mathrm{ICU}$ admissions in Spain. Med Intensiva. 2011;35:208-16.

19. Arriola CS, Anderson EJ, Baumbach J, Bennett N, Bohm S, Hill M, et al. Does influenza vaccination modify influenza severity? Data on older adults hospitalized with influenza during the 2012-2013 season in the United States. J Infect Dis. 2015;212:1200-8.

20. Rodríguez A, Díaz E, Martín-Loeches I, Sandiumenge A, Canadell L, Díaz JJ, et al. Impact of early oseltamivir treatment on outcome in critically ill patients with 2009 pandemic influenza A. J Antimicrob Chemother. 2011;66:1140-9.

21. Diaz E, Martin-Loeches I, Canadell L, Vidaur L, Suarez D, Socias L, et al. Corticosteroid therapy in patients with primary viral pneumonia due to pandemic (H1N1) 2009 influenza. J Infect. 2012;64:311-8.

22. Martín-Loeches I, Bermejo-Martin JF, Vallés J, Granada R, Vidaur L, VergaraSerrano JC. Macrolide-based regimens in absence of bacterial co-infection in critically ill H1N1 patients with primary viral pneumonia. Intensive Care Med. 2013;39:693-702.

23. Masclans JR, Pérez M, Almirall J, Lorente L, Marqués A, Socias L, Vidaur L, Rello J. Early non-invasive ventilation treatment for severe influenza pneumonia. Clin Microbiol Infect. 2013;19:249-56.

24. Centers for Disease Control and Prevention. (CDC). Interim Recommendations for Clinical Use of Influenza Diagnostic Tests During the 2009-10 Influenza Season. http://www.cdc.gov/h1n1flu/guidance/diagnostic tests.htm Accessed 26 Mar 2016.
25. Mandell LA, Wunderink RG, Anzueto A, Bartlett JG, Campbell GD, Dean NC, et al. Infectious Diseases Society of America/American Thoracic Society consensus guidelines on the management of community-acquired pneumonia in adults. Clin Infect Dis. 2007:44 Suppl 2:S27-72.

26. Knaus WA, Wagner DP, Draper EA, Zimmerman JE. APACHE II: a severity of disease classification system. Crit Care Med. 1985;13:818-29.

27. Vincent JL, Moreno R, Takala J, Willatts S, De Mendonça A, Bruining H, et al. The SOFA (Sepsis-related Organ Failure Assessment) score to describe organ dysfunction/failure. Intensive Care Med. 1996;22:707-10.

28. Sebastian MG, Lodha R, Kabra SK. Swine origin influenza (Swune flu). Indian J Pediatr. 2009;76:833-41.

29. Cowling BJ, Fang VJ, Riley S, Peiris JSM, Leung GM. Estimation of the serial interval of influenza. Epidemiology. 2009;20:344-7.

30. Cao B, Li XW, Mao Y, Wang J, Lu HZ, Liang ZA, et al. Clinical features of the initial cases of 2009 pandemic influenza A (H1N1) virus infection in China. N Engl J Med. 2009;36:2507-17.

31. Tom BD, Van Hoek AJ, Pebody R, McMenamin J, Robertson C, Catchpole M, De Angelis D. Estimating time to onset swine influenza symptoms after initial novel a (H1N1) viral infection. Epidemiol Infect. 2011;139:1418-24.

32. Rodríguez A, Alvarez-Rocha L, Sirvent JM, Zaragoza R, Nieto M, Arenzana A, et al. Recommendations of the Infectious Diseases Work Group (GTEI) of the Spanish Society of Intensive and Critical Care Medicine and Coronary Units (SEMICYUC) and the Infections in Critically III Patients Study Group (GEIPC) of the Spanish Society of Infectious Diseases and Clinical Microbiology (SEIMC) for the diagnosis and treatment of influenza A/H1N1 in seriously ill adults admitted to the intensive care unit. Med Intensiva. 2012:36:103-37.

33. Abraham MK, Perkins J, Vilke GM, Coyne CJ. Influenza in the emergency department: vaccination, diagnosis, and treatment: clinical practice paper approved by American Academy of Emergency Medicine Clinical Guidelines Committee. J Emerg Med. 2016;50:536-42.

\section{Submit your next manuscript to BioMed Central and we will help you at every step:}

- We accept pre-submission inquiries

- Our selector tool helps you to find the most relevant journal

- We provide round the clock customer support

- Convenient online submission

- Thorough peer review

- Inclusion in PubMed and all major indexing services

- Maximum visibility for your research

Submit your manuscript at www.biomedcentral.com/submit
C) Biomed Central 